\title{
Stress and Wear Analysis of the Disc Cutter of Rock Tunnel Boring Machine
}

\author{
Sun Jian ${ }^{*}, 1$, Zhou Peng ${ }^{1}$, Wu Yuhou ${ }^{1}$, Yao Jinmei ${ }^{1}$, Zou Defang ${ }^{1}$ and Liu Min ${ }^{2}$ \\ ${ }^{I}$ School of Transport and Mechanical Engineering, Shenyang Jianzhu University, Shenyang, Liaoning, 110168, P.R. \\ China \\ ${ }^{2}$ Northern Heavy Industries Group Co., Ltd, Shenyang, Liaoning, 110141, P.R. China
}

\begin{abstract}
Full face rock tunnel boring machine is one of the main machineries and equipments for underground engineering, and the failure of its disc cutter is the main failure form of this machinery. In order to find out the factors of wear of disc cutters and improve the rock breaking efficiency, a lot of research has been done. In this paper, the methods of theoretical research, simulation analysis and engineering application are used. The laws of wear of disc cutters on the cutter head are researched at the process of cutting migmatitic gneiss, and its influence factors are analyzed. The results show that the wear on the edge of disc cutter is serious. The main factor for the wear of disc cutters is its stress from the rocks, and its variance is continual. And wear rate of the disc cutters is proportional to the integrality index of the rocks. With the increase of the amount of wear, the area of contact between a disc cutter and the rock gets bigger, and their extrusion strength gets lower on the contrary. These results are very helpful to the structure optimization of the disc cutter and the improvement of working efficiency.
\end{abstract}

Keywords: Cutter blade, Disc cutter, Full face rock tunnel boring machine, Migmatitic gneiss, Stress analysis, Wear analysis.

\section{INTRODUCTION}

With the fast development of Chinese economy, there are more and more underground engineering constructed in our country. Many of them would be constructed in a rocky environment, and a full face rock tunnel boring machine is the equipment for underground engineering. However, the cost of this equipment and its operation are expensive, and the cost caused by failure of the equipment is a great proportion. It is showed by many applications that the failure of disc cutters is the main form of its failure. And the main form of the failure of disc cutters is its wear.

Properties of the rocks buried deep underground are intricate [1, 2]. In order to increase the efficiency and working life of the full face rock tunnel boring machine, the stress and wear of its disc cutters should be studied. So the cost of using this machine would be lower. Wearing situation of the disc cutters has been studied based on the method of forecasting energy by Wang [3]. The arrangement of disc cutters on the cutter head has been studied by Hao [4] and Sun [5]. The effects on the rock breaking from limiting stress at the process of cutting rocks have been studied by Ma [6]. Vibration characteristics and wear of the disc cutters were studied by Tanimoto [7]. The arrangement of disc cutters on the cutter head has been optimized by Zhaohuang Zhang [8]. The main parameter of the machine has been studied based on optimization methods by Zhijie Liu [9]. Stress and

*Address correspondence to this author at the School of Transport and Mechanical Engineering, Shenyang Jianzhu University, Shenyang, Liaoning, 110168, P.R. China; Tel: 18704060327 ;

E-mail: sun503529@126.com vibration of the disc cutters of a TBM were analyzed by Liu [10]. The reason cutter head get breakage has been studied by Hongliang Li [11]. And the method of protecting cutter head was given by him. The failure of disc cutters has been research by $\mathrm{Hu}$ [12]. The stress of disc cutters and the strain of rocks at the process of cutting rocks have been studied by Ke Zhang [13]. The effects on stress and strain of disc cutters from its penetration also have been studied by him. His results show that if the amount of penetration of disc cutters reaches $0.76 \mathrm{~mm}$, the rocks would be broken. The areas of stress and the areas of strain on the rocks are proportional to the amount of penetration. The process of cutting rocks by disc cutters has been studied by Yuhou Wu [14]. He has researched the broken and strained areas of the rocks based on its properties and stress. The results show that, for the same cutter payload, the crush areas and the deformation areas occurred in different rocks are different because of their different ultimate stress, elastic modulus, and Poissons Ratio. The crush areas of the rocks are proportional to the cutter payload. The stress areas of the rocks are inversely proportional to its Poissons Ratio, and the deformation areas of a rock are inversely proportional to its elastic modulus.

In order to understand the rock breaking mechanism, improve the rock breaking efficiency, optimize the structure of disc cutters and extend its service life, stress and vibration of the disc cutters have been studied based on its mechanical model in this paper. Law of disc cutters wear is analyzed by the application of engineering data. The results of this paper are very helpful for the structure optimization of tool system and the improvement of working efficiency. 


\section{STRESS ANALYSIS OF DISC CUTTERS}

\subsection{Mechanical Model of Disc Cutters}

The diameter of disc cutters of a full face rock tunnel boring machine is $432 \mathrm{~mm}$, and its material is $40 \mathrm{CrNiMoA}$. The disc cutters break rocks under the driving force provided by cutter head. The mechanical model diagrams of the disc cutters at the process of cutting rocks are shown at Fig. (1). The force of a disc cutter could decomposed into a vertical force $V_{f}$, a tangential force $R_{f}$, and a lateral force. The amount of lateral force is so small compared with vertical force and tangential force. So the lateral force of disc cutters is often ignored at the time of analyzing its force.

(a) Mechanical model of rolling

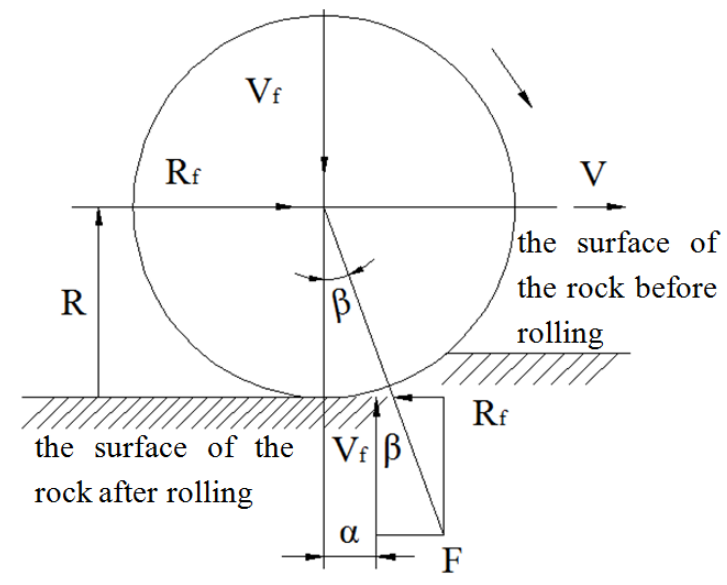

(b) Mechanical model of penetrating

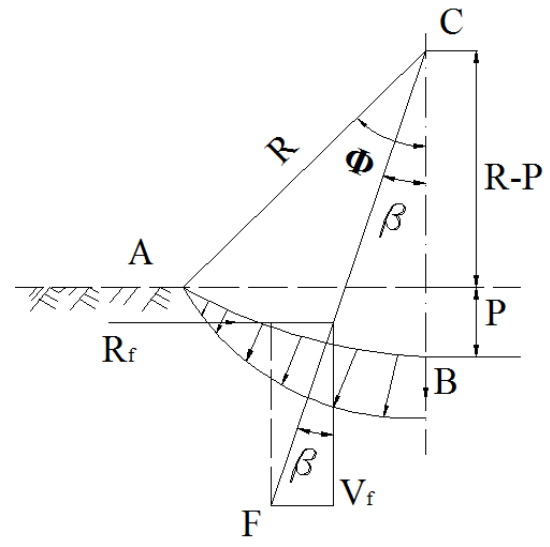

(c) Mechanical model of cut spacing

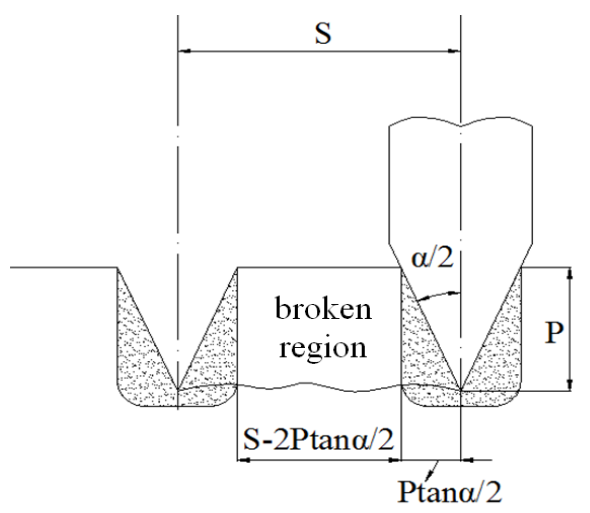

Fig. (1). Mechanical model diagrams of the disc cutters.

$$
\begin{aligned}
& V_{f}=D^{0.5} P^{1.5}\left[\frac{4}{3} \sigma+2 \tau\left(\mathrm{S}-2 P \tan \frac{\alpha}{2}\right)\right] \tan \frac{\alpha}{2} \\
& R_{f}=\left[\sigma P^{2}+\frac{4 \tau \phi P^{2}\left(S-2 P \tan \frac{\alpha}{2}\right)}{D(\phi-\sin \phi \cos \phi)}\right] \tan \frac{\alpha}{2}
\end{aligned}
$$

In the above equation, $D$ is diameter of the cutter head. $S$ is the spacing between two disc cutters. $P$ is the penetration of disc cutters. $\delta$ is the uniaxial compressive strength of rocks. $\tau$ is the shear strength of rocks. $\alpha$ is the angle of cutter blade. $\phi$ is the angle of indentation between cutter blade and rock.

Plastic mathematical model named Drucker-Prager for cutting rocks is built by author based on elastic-plastic model and failure criterion of the rocks. According to the characteristics of breaking rocks, there are two assumed conditions for the process of building the model.

1. Material properties of the rocks are isotropic, continuous and uniform;

2. The breaking process of the rocks could divide into three stages: elastic deformation, plastic deformation and breakage stage.

Yield functions of the mathematical model for cutting rocks are obtained as follows:

$$
\left\{\begin{array}{l}
F=t-p \tan \beta-d=0 \\
t=\frac{q}{2}\left[1+\frac{1}{k}-\left(1-\frac{1}{k}\right)\left(\frac{r^{3}}{q}\right)\right]
\end{array}\right.
$$

In the above equation, $t$ is deviatoric stress. $P$ is equivalent pressure stress. $\beta$ is the slope of linear yield surface. $d$ is the cohesion of materials. $q$ is Mises equivalent stress. $r$ is the third invariant of deviatoric stress. $k$ is the ratios between experimental yield stresses on triaxial extension and triaxial compression. The relation between yield surface and principal stress are expressed by the $k$. And its diagram is shown at Fig. (2).

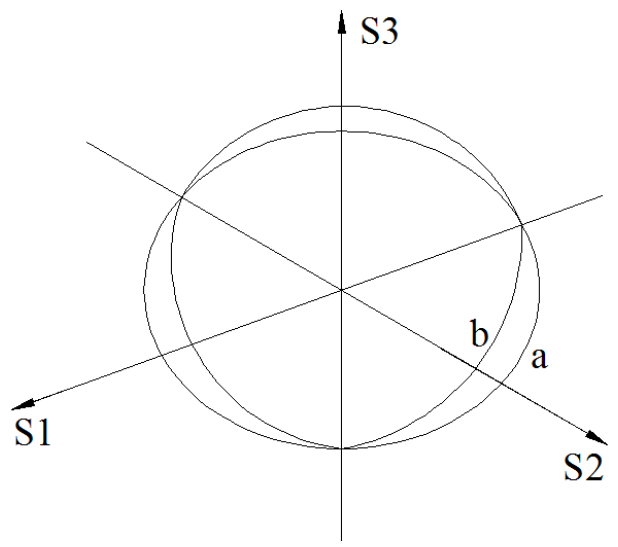

Fig. (2). The relation between yield surface and principal stress.

\subsection{Stress Distribution of Disc Cutters}

According to the above mechanical model of disc cutters, the process of cutting rocks is simulated by ANSYS. Distribution of stress on the edge of disc cutter is got, and it is shown at Fig. (3). 

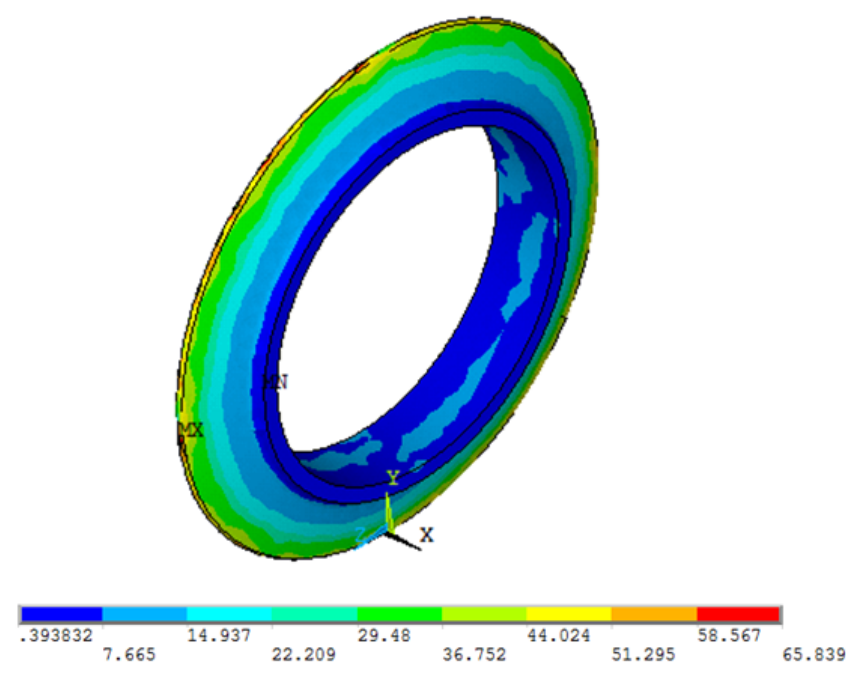

Fig. (3). The distribution of stress on the edge of disc cutter.

From the Fig. (3) it can be seen that the value of stress on contact area between the disc cutter and the rock is maximum. The contact area is the stress concentrated area, and the direction of principal stress points to the centre of disc cutter. The value of stress on the edge of disc cutter is reduced along with the direction of principal stress. Because the disc cutter is scrollable at the process of cutting rocks and the stress on a region of disc cutter is variable, so this stress is alternating stress. However, the alternating stress of a disc cutter has an important influence on its wear. Generally, for isotropic and uniform object, the area of maximum stress would have a maximum wear value. So from Fig. (3) it can be seen that the edge of disc cutter has a maximum wear value at the process of cutting rocks.

\section{ANALYSING THE WEAR OF DISC CUTTERS}

There are a lot of factors to affect the wear of disc cutters at the process of cutting rocks. The factors contain the size of the disc cutter, the material of the disc cutter, geometry structure of the cutter blade, the types of rock and so on. Analyzing stress and wear of the disc cutters based on ANSYS, it can seen that with the longtime of cutting rocks the cutter blade become passivated and its angle is flattening at the process of cutting rocks. So the geometry structure of the cutter blade is changed and the stress on the disc cutter is change too, shown as Fig. (4).

According to Fig. (4a), when the cutter blade is unworn, the stress on surface of migmatitic gneiss is $289 \mathrm{MPa}$. The crack and broken regions of migmatitic gneiss are also shown at Fig. (4a). After long time of cutting rocks, cutter blade becomes passivated and the stress on migmatitic gneiss is changed as shown at Fig. (4b). It can be seen that when the cutter blade is worn, the stress on surface of migmatitic gneiss is $265 \mathrm{MPa}$. Its crack and broken regions are also shown at this figure.

Comparing with the two figures we can see that the extrusion strength between disc cutter and migmatitic gneiss would become lower by worn disc cutter. Furthermore, the area of crack on migmatitic gneiss would get bigger and its broken area would get smaller if the cutter blade of disc cutter becomes passivated. The reasons for the above phenomenon are that if the contact area between disc cutter and migmatitic gneiss get bigger, the stress on the migmatitic gneiss would become smaller at the same propulsion provided by disc cutter. So extrusion strength becomes lower. When extrusion strength of migmatitic gneiss is smaller than its limiting stress, migmatitic gneiss would not be broken. And the broken region of migmatitic gneiss would also get smaller. Because the contact area becomes bigger, the area of stress on the migmatitic gneiss would get bigger. So its crack regions would also get bigger.

\section{(a) Unworn disc cutter}

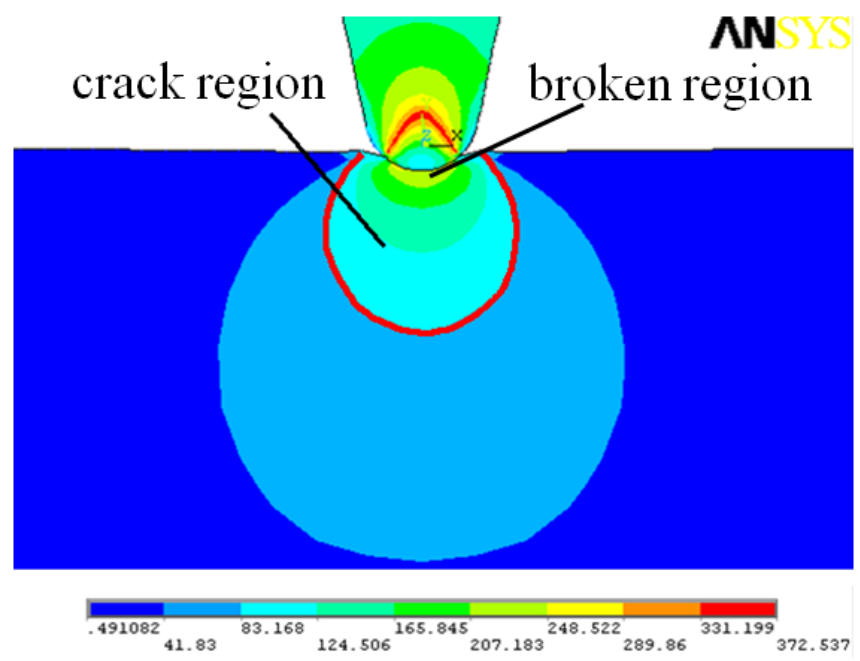

(b) Worn disc cutter

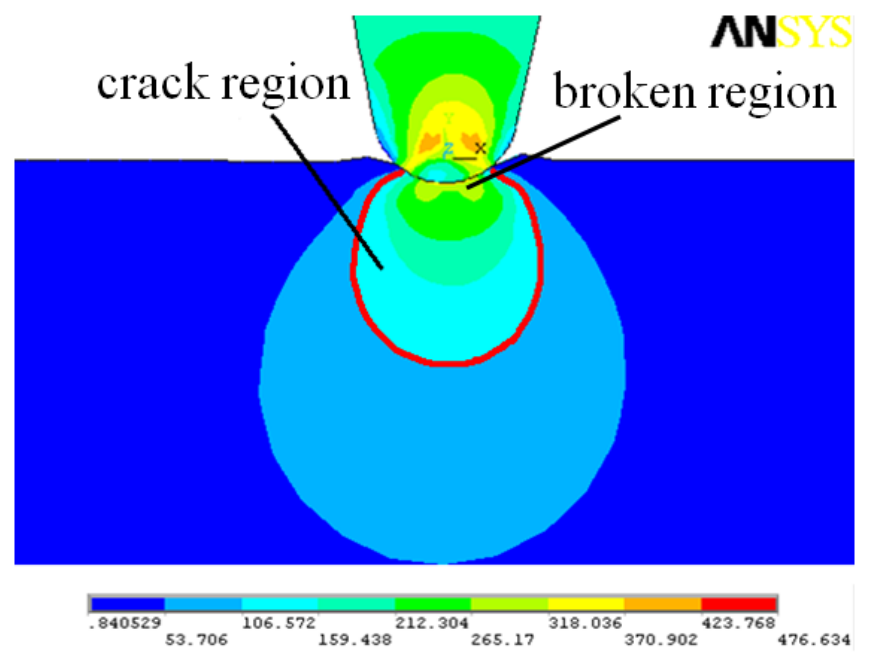

Fig. (4). The stress of cutting migmatitic gneiss by different wearing disc cutters.

Table $\mathbf{1}$ is a relational table between extrusion strength to rocks and excavated speed of full face rock tunnel boring machine. According to this table, it can be seen that excavated speed of the machine would get reduced if the extrusion strength and the hardness of the rocks get bigger. And the wear of disc cutters would also get bigger.

Through the above-mentioned simulation, it can be seen that the contact area between a disc cutters and the rock is inversely proportional to the extrusion strength. The relation between wear of the disc cutter and the contact area is shown at Fig. (5). The relation between wear of the disc cutter and extrusion strength to migmatitic gneiss is also shown at 
Table 1. The relation between extrusion strength of rocks and excavated speed of full face rock tunnel boring machine.

\begin{tabular}{|c|c|c|c|c|c|}
\hline The kind of Rocks/Extrusion Strength (MPa) & Sandstone/45 & Slate/110 & Schist/140 & Gneiss/135-280 & Migmatitic Gneiss/150-280 \\
\hline \hline Excavated speed $(\mathrm{m} / \mathrm{h})$ & 1.95 & 1.35 & 1.05 & 0.9 & 0.85 \\
\hline
\end{tabular}

Fig. (5). According to the data in Fig. (5), the contact area between the disc cutter and the rock become bigger when the wear of disc cutter gets bigger. So the stress on surface of the rock and the extrusion strength to it would get smaller. And the efficiency of rock broken would also get lower.

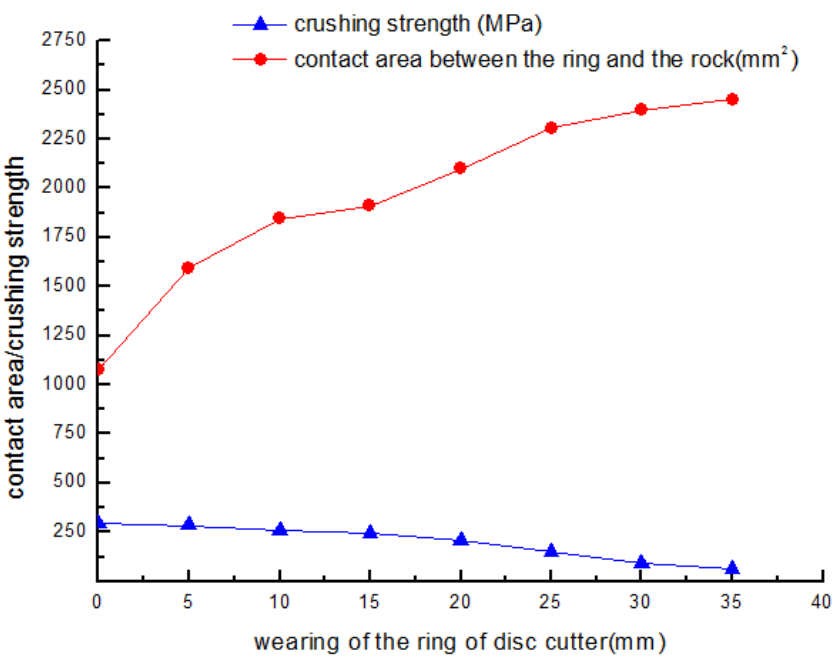

Fig. (5). The relation between wear of the disc cutter and the contact area and the extrusive intensity.

The relation between the rate of consumption for disc cutters and complete coefficient of the rocks is shown at Fig. (6). The rock of the tunnel is migmatitic gneiss and excavated speed of tunnel boring machine is $1.18 \mathrm{~m} / \mathrm{h}$. The complete coefficient of migmatitic gneiss is inversely proportional to its coefficient of crack. From this figure, it can be seen that the amount of consumed disc cutters is increased when complete coefficient of migmatitic gneiss is growing up. The reason of this phenomenon is that internal

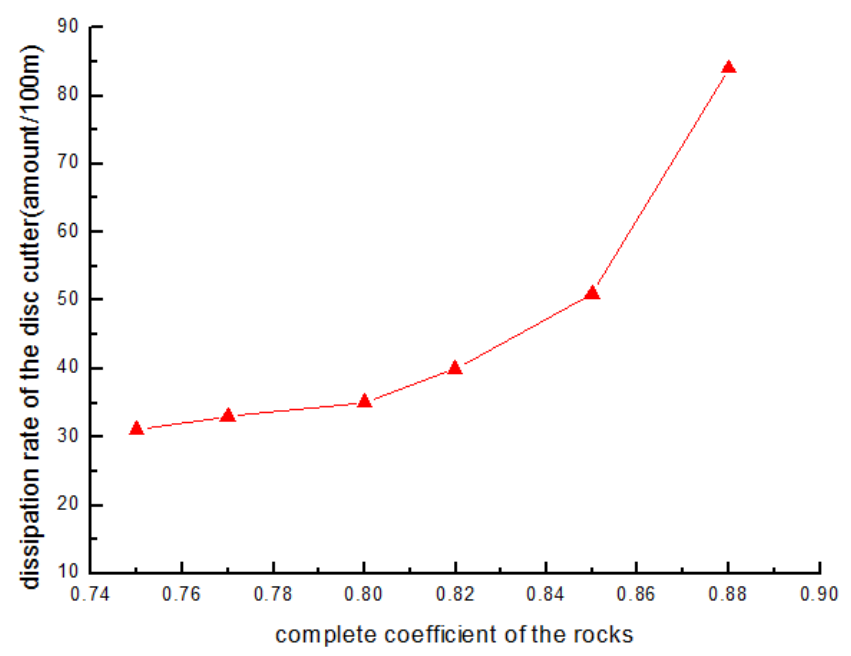

Fig. (6). The relation between coefficient of the rocks and the rate of consumption of disc cutters. strength of the rocks is proportional to its complete coefficient. If internal strength of the rocks is bigger, the removal force for breaking the surface of rocks is bigger too. So the wearing of disc cutters would be increased.

\section{CONCLUSION}

The stress on disc cutters is analyzed at the process of cutting rocks. The consumption regulation of the disc cutters and its influential factor are researched based on cutting migmatitic gneiss. The conclusion is as follows:

1. The stress on the edge of disc cutters is greatest at the process of tunneling. So it is the part of most easy to wear for a disc cutter. Because the stress on a region of a disc cutter is variable, so this stress is an alternating stress. However, the alternating stress has an important influence on its wear;

2. When the wearing of a disc cutter is increased, the contact area between a disc cutter and the rock would get bigger. The extrusion strength to the rock would become smaller and its broken area gets smaller too. But, if the contact area becomes bigger, the area of stress on the rock would get bigger. So its crack regions would get bigger;

3. The internal strength of the rocks is proportional to its complete coefficient. If internal strength of the rocks is bigger, the removal force for breaking the surface of rocks is bigger too. So the wearing of disc cutters would be increased.

\section{CONFLICT OF INTEREST}

The authors confirm that this article content has no conflict of interest.

\section{ACKNOWLEDGEMENTS}

This work was financially supported by National Key Technology R\&D Program (2011BAJ02B07), Liaoning University Innovation Team Program (LT2014011), Shenyang Jianzhu University Young Foundation (2014008).

\section{REFERENCES}

[1] Z. Li, X. Jiang, and W. Yu, "Analysis on ultimate bearing capacity of overlying rock in deep mining," Journal of Liaoning Technical University Natural Science, vol. 29, no. 6, pp. 1013-1015, 2010.

[2] S. Li, G. Z. Shang, W. Sun, and C. Kang, "Simulation on relationship between hydraulic conductivity and porosity for porous soils," Journal of Liaoning Technical University Natural Science, vol. 29, no. 4, pp. 589-592, 2010.

[3] L. Wang, Y. Kang, Z. Cai, Q. Zhang, Y. Zhao, H. Zhao, and P. $\mathrm{Su}$, "The energy method to predict disc cutter wear extent for hard rock TBMs," Tunnelling and Underground Space Technology, vol. 28, no. 1, pp. 183-191, 2012.

[4] J. Huo, W. Sun, J. Chen, and X. Zhang, "Disc cutters plane layout design of the full-face rock tunnel boring machine (TBM) 
based on different layout patterns," Computers and Industrial Engineering, vol. 61, no. 4, pp. 1209-1225, 2011.

[5] W. Sun, J. Huo, J. Chen, Z. Li, X. Zhang, G. Li, H. Zhao, and Y. Zhao, "Disc cutters layout design of the full-face rock tunnel boring machine (TBM) using a cooperative coevolutionary algorithm," Journal of Mechanical Science and Technology, vol. 25, no. 2, pp. 415-427, 2011.

[6] H. Ma, L. Yin , and H. Ji, "Numerical study of the effect of confining stress on rock fragmentation by TBM cutters," International Journal of Rock Mechanics and Mining Sciences, vol. 48, no. 6, pp. 1021-1033, 2011.

[7] C. Tanimoto, S. Yamanaka, K. Tsusaka, T. Nakane, M. Hirano, H. Kanzaki, S. Abe, and S. Iwata, "A study on cutter wear and mechanical properties of rocks in tunneling with a TBM," Journal of the Society of Materials Science, vol. 55, no. 1, pp. 29-36, 2006.

[8] Z. Zhang, and Y. Qiao, "Research on the layout of disc cutter," Engineering Mechanics, vol. 28, no. 5, pp. 172-177, 2011.

[9] Z. Liu, Y. Shi, and H. Teng, "Case-based reasoning approach for cutterhead principal parameter design of full face rock tunnel boring machine," Journal Of Mechanical Engineering, vol. 46, no. 3, pp. 158-164, 2010.

[10] P. Liu, Y. Gong, and C. Wang, "Finite element simulation analysis for cutter head of Slurry Balance TBM," Advanced Materials Research, vol. 482-484, pp. 1257-1260, 2012.

[11] H. Li, "Troubieshooting for cutter disk cracking of model TB880 rock thnneier," Operation and Maintenance, vol. 41, pp. 62-67, 2010.

[12] L. Hu, R. Yuan, H. Chen, and Y. Bai, "Failure modes and effects analysis on ITER DFLL-TBM system," Fusion Engineering and Design, vol. 7-8, pp. 1307-1309, 2012.

[13] K. Zhang, T. Wang, H. Sun, H. Wang, and K. Zhao, "Simulation study on disc cutter of full face rock tunnel boring machine," Journal of Shenyang Jianzhu University (Natural Science), vol. 26, pp. 1209-1213, 6, 2010.

[14] Y. Wu, J. Sun, P. Zhou, and H. Sun, "Research on the adaptability of TBM disc cutter to the character of rocks," Journal of Shenyang Jianzhu University (Natural Science), vol. 28, pp. 156-161, 1, 2012.

(C) Jian et al.; Licensee Bentham Open.

This is an open access article licensed under the terms of the Creative Commons Attribution Non-Commercial License (http://creativecommons.org/licenses/by-nc/4.0/) which permits unrestricted, non-commercial use, distribution and reproduction in any medium, provided the work is properly cited. 